\title{
Review Article \\ Extracellular Membrane Vesicles as Vehicles for Brain Cell-to-Cell Interactions in Physiological as well as Pathological Conditions
}

\author{
Gabriella Schiera, ${ }^{1}$ Carlo Maria Di Liegro, ${ }^{1}$ and Italia Di Liegro ${ }^{2}$ \\ ${ }^{1}$ Dipartimento di Scienze e Tecnologie Biologiche, Chimiche e Farmaceutiche (STEBICEF), Università degli Studi di Palermo, \\ 90128 Palermo, Italy \\ ${ }^{2}$ Dipartimento di Biomedicina Sperimentale e Neuroscienze Cliniche (BIONEC), Università degli Studi di Palermo, \\ 90127 Palermo, Italy
}

Correspondence should be addressed to Italia Di Liegro; italia.diliegro@unipa.it

Received 27 March 2015; Revised 27 May 2015; Accepted 28 May 2015

Academic Editor: Aurelio Lorico

Copyright (C) 2015 Gabriella Schiera et al. This is an open access article distributed under the Creative Commons Attribution License, which permits unrestricted use, distribution, and reproduction in any medium, provided the original work is properly cited.

Extracellular vesicles are involved in a great variety of physiological events occurring in the nervous system, such as cross talk among neurons and glial cells in synapse development and function, integrated neuronal plasticity, neuronal-glial metabolic exchanges, and synthesis and dynamic renewal of myelin. Many of these EV-mediated processes depend on the exchange of proteins, mRNAs, and noncoding RNAs, including miRNAs, which occurs among glial and neuronal cells. In addition, production and exchange of EVs can be modified under pathological conditions, such as brain cancer and neurodegeneration. Like other cancer cells, brain tumours can use EVs to secrete factors, which allow escaping from immune surveillance, and to transfer molecules into the surrounding cells, thus transforming their phenotype. Moreover, EVs can function as a way to discard material dangerous to cancer cells, such as differentiation-inducing proteins, and even drugs. Intriguingly, EVs seem to be also involved in spreading through the brain of aggregated proteins, such as prions and aggregated tau protein. Finally, EVs can carry useful biomarkers for the early diagnosis of diseases. Herein we summarize possible roles of EVs in brain physiological functions and discuss their involvement in the horizontal spreading, from cell to cell, of both cancer and neurodegenerative pathologies.

\section{Introduction}

Extracellular vesicles (EVs) are membrane structures that can be divided into two subgroups: membrane vesicles (MVs), also named ectosomes [1], that derive from plasma membrane exocytosis and have dimensions in the range of $100 \mathrm{~nm}-1 \mu \mathrm{m}$ and exosomes that are smaller vesicles of 50 $100 \mathrm{~nm}$ in diameter, generated by exocytosis of multivesicular bodies (MVBs) [2]. The two classes of EVs share membrane components, but each of them also contains peculiar proteins, some of which are cell-specific [1]. Lipid composition is also peculiar; MVBs are enriched with specific lipids, probably involved in membrane budding, such as cholesterol, the unconventional phospholipid lysobisphosphatidic acid, sphingomyelins, and ceramide $[1,3-6]$. Similarly, cholesterol, sphingomyelin, and ceramide also segregate during ectosomes formation at the plasma membrane [7]. It has been suggested that sorting of proteins to ectosomes is largely based on their interaction with the membrane through their lipid anchors which concentrate them to specific plasma membrane microdomains $[8,9]$.

Specific enrichment of both proteins and lipids in EVs not only suggests the existence of underlying regulatory mechanisms, which allow selection of cargos, but also points to an important role of EVs in the normal tissue physiology. As a confirmation of such a central role, it is now clear that vesicle release is a universal phenomenon, representing a novel and significant way to shuttle different molecules, such as protein, DNA, and RNA among cells, not only in eukaryotic organisms, but also in prokaryotes $[10,11]$. 
Moreover, although vesicle release was initially discovered in tumor cells [12-16], vesicles are clearly produced by several nontumor cells [17-21] and can reach most biological fluids, such as blood plasma [22], synovial fluids [23, 24], breast milk [25], and saliva [26, 27], where, in addition, their concentration can dramatically change under pathological conditions.

Although EVs have been finally accepted as significant vehicles for cell-to-cell communication and they have been identified in a variety of organisms and conditions, two main problems remain, however, unsolved:

(1) the actual role of these vesicles in the integrated behavior of tissues and organs;

(2) the reason why production of EVs and specific sorting of cargos to them are altered in pathological conditions as different as cancer and neurodegeneration.

Moreover, since most studies have been performed on EV mixtures, it is still unclear whether these different classes of vesicles are equally involved in physiological and pathological processes.

Here we summarize the possible physiological roles of EVs in the nervous system and discuss their involvement in the horizontal transfer of brain pathologies.

\section{Vesicles in Brain Normal Cells}

Cell-to-cell communication is determinant for the right mammalian brain maturation to regulate differentiation of neurons, endothelial and glial cells, as well as allow formation and stabilization of synapses. Cross talk among different classes of brain cells is also essential to generate the bloodbrain barrier (BBB), which then maintains brain internal milieu, by controlling trafficking of molecules and ions between the brain and the blood [28]. For example, in a transwell coculture system, containing both rat cortical astrocytes and neurons, brain capillary endothelial cells (BCECs) were found to form over time a functional barrier layer, even in the absence of cell-to-cell contacts $[29,30]$. Further analyses demonstrated that both neurons [19] and astrocytes [20] release into the medium, at least in part by EVs, Vascular Endothelial Growth Factor (VEGF) and Fibroblast Growth Factor 2 (FGF-2; also known as basic FGF), two growth factors which promote vascularization of developing brain. Both factors are also involved in abnormal neovascularization processes which accompany several pathological conditions [31, 32]. Interestingly, FGF-2 has been known since a long time ago to be secreted in spite of lacking a conventional secretion sequence and independently of the classical cell secretion pathway [33].

One of the main problems in studying metabolism of EVs has been to understand how their content reaches target cells. There is now evidence that their cargos can be at least partially transferred into the recipient cells, through fusion of EVs to the target plasma membranes. For example, after being released via EVs from metabolically labeled astrocytes/neurons, radioactive proteins have been found in unlabeled endothelial cells (Figure 1).

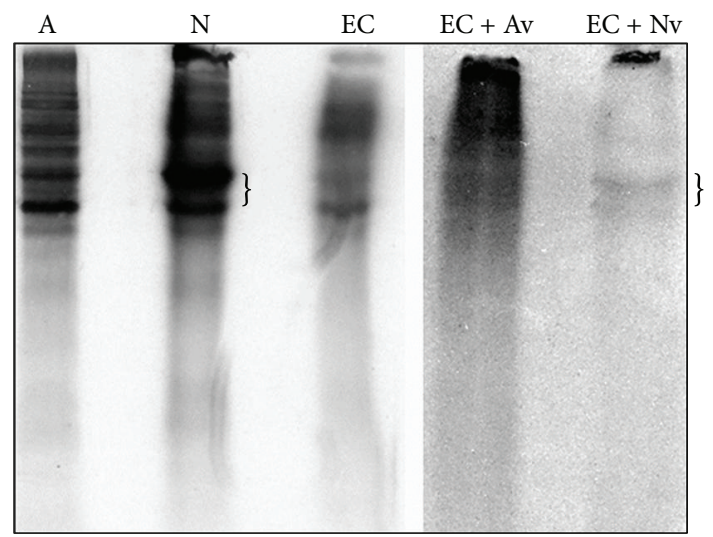

FIGURE 1: Fluorography of total cell lysates from astrocytes (A), neurons $(\mathrm{N})$, and endothelial cells (EC), metabolically labeled with ${ }^{35} \mathrm{~S}$ methionine, as well as from unlabeled endothelial cells, incubated for 24 hours with microvesicles shed from labeled astrocytes (EC + $\mathrm{Av})$ or neurons $(\mathrm{EC}+\mathrm{Nv})$. The brackets indicate bands present in both labeled neurons and endothelial cells incubated with vesicles shed from neurons.

As mentioned, extracellular vesicles also contain mRNAs and different species of noncoding RNA. Given the importance of RNA-binding proteins (RBPs) in posttranscriptional regulation, mRNAs in vesicles are probably bound to proteins in the form of ribonucleoprotein particles. In agreement with this hypothesis, a microarray analysis, performed on vesicles purified from the cerebrospinal fluid (CSF), recently demonstrated the presence of RNAs containing the recognition sequence for hnRNPA2/B1, an RBP present in the same vesicles, probably in sumoylated form. Moreover, sumoylation has been shown to control hnRNPA2/B1 binding to miRNAs and sorting of these RNAs to exosomes [34]. Both the amount of vesicles and the number of mRNA molecules which bear the hnRNPA2/B1 recognition sequence decrease with development [35].

When we consider the complexity of vesicle cargos, it is not surprising that EVs also contain molecular chaperones and other factors which can regulate protein folding as well as protein-protein and protein-nucleic acid interactions. MVs and exosomes released from astrocytes not only contain, for example, Hsc70/Hsp70 [36, 37] and synapsin I [38], but also matrix metalloproteinases [39], which could be involved in extracellular matrix remodeling. This latter ability is fundamental for tumor cells invasion and migration; however, which function could it have in normal astrocytes or neurons? To answer the question, it could be useful to consider that most brain cells are able to grow branched cellular processes, which can explore the environment, migrate, and contact other cells; thus, an intrinsically high ability to modify the surrounding environment is critical for these cells.

Interestingly, in vitro studies demonstrated that release of exosomes from neurons can be modulated by synaptic activity [40]; by functioning as vehicles for both anterograde and retrograde information transfer, exosomes could be then involved in synaptic plasticity and long-term memory [41]. 


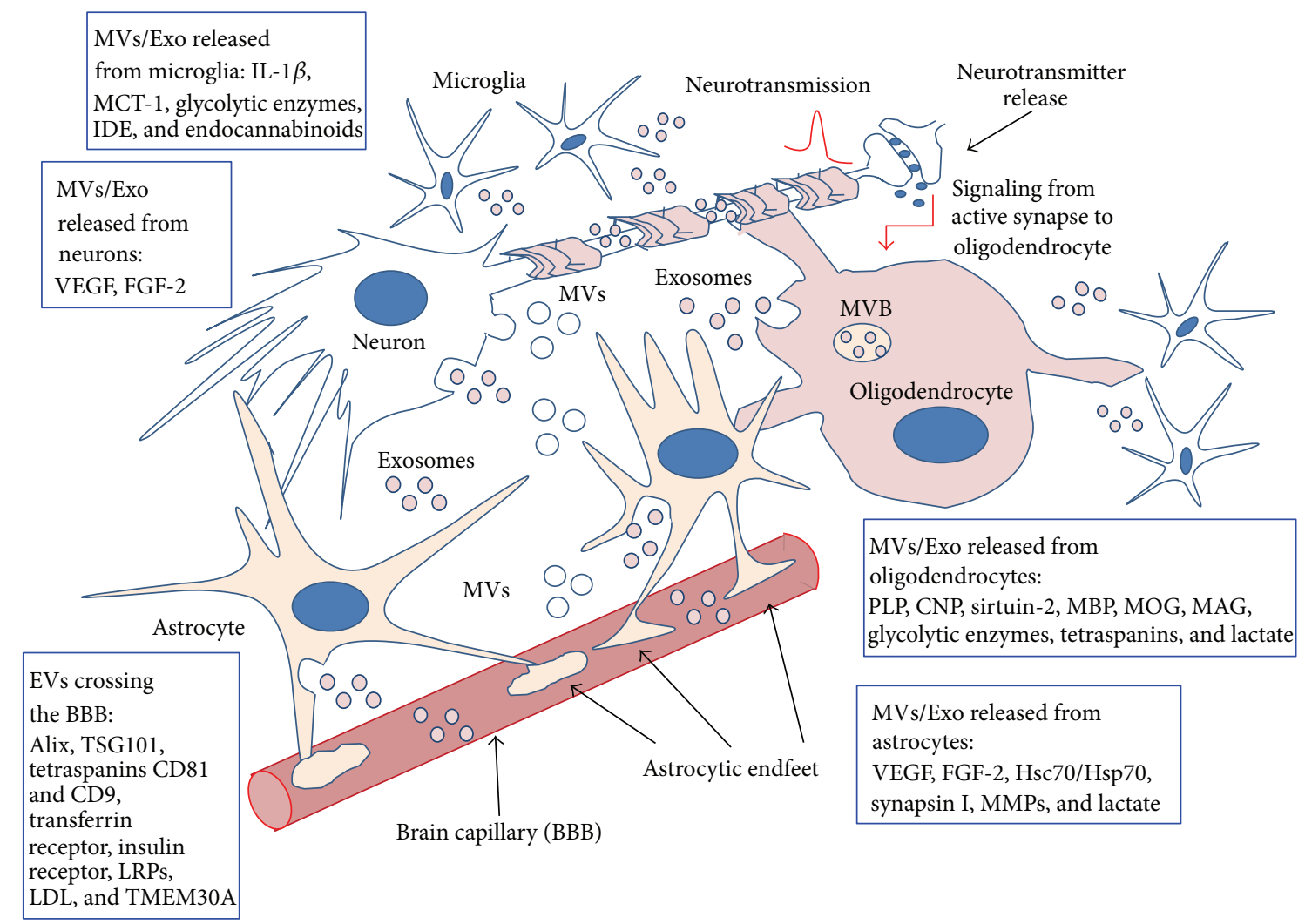

FIGURE 2: Extracellular membrane vesicles as vehicles for brain cell-to-cell interactions. As shown, all kinds of brain cells can both produce EVs and receive those produced by surrounding cells; this continuous exchange could be a fundamental source of metabolic coupling among neurons and glial cells. Vesicle trafficking from glial cells to neurons has been also suggested to be regulated by neurotransmission, as indicated by the red arrow in the figure. A few examples of molecules present in EVs released from the various brain cell types are given in the boxes. More details and related references are given in the text.

Vesicles are also released from oligodendrocytes, the glial cells responsible in the CNS for producing the myelin sheath which coats the axons, allowing fast impulse conduction; in addition, like astrocytes, oligodendrocytes have a trophic function and provide neurons with energetic substrates, such as lactate [42-44]. The continuous axon-oligodendrocyte cross talk seems to be mostly based on transfer of vesicles [42] which contain myelin proteins, such as proteolipid protein (PLP), 2' $3^{\prime}$-cyclic-nucleotide $3^{\prime}$-phosphodiesterase (CNP), myelin-associated glycoprotein (MAG), myelin oligodendrocyte glycoprotein (MOG), NAD-dependent deacetylase sirtuin-2, glycolytic enzymes, heat-shock proteins, and tetraspanins [45]. It has been also reported that proximal segments of transected sciatic nerves accumulate newly synthesized RNA in axons and that these mRNAs are actually synthesized in Schwann cells and then transferred to neurons through a mechanism that requires actin cytoskeleton and myosin-Va [46].

Most important, vesicle trafficking from glial cells to neurons has been suggested to be regulated by neurotransmission (Figure 2): an increase of cytosolic $\mathrm{Ca}^{2+}$ levels in oligodendrocytes, due to activation of glutamate receptors, present on glial cell membrane, induces exosome release [47]. Actually, active neurons should ask oligodendrocytes for metabolites, regulatory proteins, glycolytic enzymes, mRNAs, and miRNAs [48].

Transfer of mRNAs from glial cells to neurons might be of special interest when we consider that localized axonal synthesis may allow remodeling of growing (or regenerating) axons during progression through their extracellular environment. Although translation of localized mRNAs in axons has been debated for a long time [49], periaxoplasmic ribosomal plaques (PARPs) have been only recently described, which contain ribosomes attached to a plaque-like structure, also enriched with $\beta$-actin mRNA, molecular motors, and RNA-binding proteins [50]. Moreover, multiple translation components, including ribosomal subunits and initiation factors, interact with the transmembrane receptor (DCC) for netrin-1, suggesting that their activity can be regulated by extracellular signals [51].

The exciting possibility that ribosomes and mRNAs could be horizontally delivered from surrounding glial cells to axons has been also proposed $[52,53]$. For example, Court and colleagues showed that GFP-tagged polyribosomes produced by glial cells can be transferred to axons both in vitro [52] and in vivo [54]. 
These findings support the idea that glial cells may contribute to local axonal protein synthesis by supplying protein synthetic machinery and specific mRNAs [55].

Another important class of brain cells is constituted by microglia, the resident macrophages of the brain, which provide the defense during infection and brain injury, and are implicated also in tissue repair. During disease, microglia acquire an activated phenotype, and release soluble mediators, to induce and maintain the inflammatory response. There is also evidence indicating that reactive microglia have the capability to release vesicles of irregular shape and size, characterized by high levels of externalized phosphatidylserine (PS) [56]. These vesicles contain IL-1 $\beta$ that may induce and propagate inflammatory reactions in the brain $[56,57]$. In addition, microglial MVs, like other glial cell types (see above), are able to modulate synaptic activity and neurotransmission [58]. For example, EVs secreted by microglia have been recently shown to expose on their plasma membrane the active endocannabinoid $\mathrm{N}$-arachidonoylethanolamine (AEA), which binds to and stimulates the type 1 cannabinoid receptors (CB1), thus inhibiting presynaptic transmission in GABAergic neurons [59]. Exosomes released by microglia also contain glycolytic enzymes and the monocarboxylate transporter 1 (MCT1); one role of these exosomes could be delivering to not only target cells energy substrates, but also special enzymes such as the insulin degrading enzyme (IDE), which can degrade the $\mathrm{A} \beta$ peptide [60].

Finally, it has been found that BCECs, the endothelial cells which constitute the wall of the brain capillaries and give rise to the blood-brain barrier, are also able to release vesicles. Interestingly, the endothelial cell-derived EVs are able to cross the $\mathrm{BBB}$ and are responsible, at least in part, for the brain-specific biomarkers found in blood; accordingly, these vesicles can be useful to analyze the time course of brain diseases. Since their membranes contain many BBB receptors, such as the transferrin and the insulin receptors, these MVs might be also used to deliver drugs across the BBB [61].

Now, if all the brain cell populations are able to release vesicles, an intriguing point is whether EVs produced by a given cell type have promiscuous activities or, on the contrary, have a specific target. Recent analyses suggested that physiological brain vesicles delivery is actually highly specific: exosomes secreted from stimulated glutamatergic cortical neurons were indeed captured only by other neurons; on the other hand, vesicles released from neuroblastoma cells lost this capability and were shown to bind both neurons and glial cells, with an apparent preference for glial cells [62].

Before concluding this brief summary concerning normal brain cells, it should be underlined that, beside their role as carriers of regulatory molecules, EVs can also function as scavengers. Some authors indeed found that exosomes/MVs are necessary for normal cells to eliminate proteins, for example, to discard an excess of glutamate receptor 2 [40].

\section{Brain Cancer Cells}

Variety and complexity of primary tumours of the Central Nervous System (CNS) are probably the highest among human cancers. Their classification is based on both the cell type and/or the brain structure from which they arise and on their grade, from I to IV, according to increasing malignancy of the cancer cells $[63,64]$.

Most brain primary tumours in the adult originate from glial cells/glial cell precursors and are collectively called gliomas, further divided into astrocytomas, oligodendrogliomas, ependymomas, and mixed oligoastrocytomas $[63,64]$. According to the grade of malignancy, oligodendrocytomas and mixed gliomas are grades II and III, while astrocytomas are grouped into low-grade (LGA: pilocytic, grade I; diffuse, grade II) and high-grade astrocytomas (HGA: anaplastic, grade III; glioblastoma multiforme, GBM, grade IV) [65].

The treatment of HGA is mainly done by surgery, also required for definitive histopathologic diagnosis $[65,66]$, followed by radiation and chemotherapy [67].

Unfortunately, these therapeutic protocols, in spite of undisputed advancements, are not actually effective, and high grade gliomas still remain almost always fatal. In addition, gliomas are difficult to diagnose at an early stage because, at the beginning, the patients may suffer from unspecific symptoms, such as headache and seizures [65]. Difficulties in diagnosing as well as in treating gliomas also depend on the particular location of these tumours, which are protected by the BBB. Many efforts have been, indeed, recently devoted to find out strategies which might improve permeability of $\mathrm{BBB}$ to CNS-directed drugs (for review see [68]), although, paradoxically, BBB leakage and the concomitant vasogenic edema (see below) are the main clinical problems in patients suffering from glioblastoma (for review see [69]). For all these reasons, new approaches are urgently needed for an early diagnosis of brain cancer and improvement of therapy.

As shown for many other tumours, brain cancers release much higher amounts of extracellular vesicles than normal cells. EVs are continuously released by cancer cells, but their concentration in the body fluids is somehow proportional to disease grade [70]. Concerning their content, beside proteins more or less present in all the EVs studied up to now, such as different classes of chaperones, they contain tumour-specific antigens, MHC I and II complexes for antigen presentation, apoptosis-inducing (such as FasL and TRAIL) and immune suppressive (such as TGF $\beta$ ) factors (see below), as well as oncogenic growth factor receptors, such as a truncated form of the epidermal growth factor receptor EGFRvIII [71, 72]. In line with these contents, it has been shown that EVs shed from tumours can facilitate cancer development by suppressing immune responses, stimulating tumour growth, invasion, angiogenesis, and metastasis.

For many decades CNS was considered somehow "invisible" to the immune system because of its protected condition, ensured by BBB. It is now clear, however, that it can be better described as an immune "specialized" site, in which the bidirectional exchange of immune cells with the circulation is fundamental for the maintenance of integrity and functions $[73,74]$. In addition, resident microglia can adopt active phagocytic behaviour and release proinflammatory factors upon brain injury $[75,76]$. In the context of gliomas, however, glioma-associated microglia and macrophages (GAMs) seem 
to loss the ability to induce antitumour immune response and to switch instead to a tumour-promoting, immunosuppressive phenotype. The inducers of this behavioural transition are glioma-derived factors, among which are TGF $\beta$, interleukin- (IL-) 4, IL-6, IL-10, and prostaglandin PGE-2 $[76,77]$. At the same time, glioma cells seem to be also able to recruit from the circulation other immature myeloid cells, which also adopt an immune suppressive behaviour, as soon as they start interacting with the cancer site [76]. The cellular and molecular bases for these phenotypic modifications of immune cells, which infiltrate the tumour, are not completely understood but certainly depend on an intense cross talk among glioma and surrounding cells, forced to conform to the signals received and involve at least in part EVs [78].

Among the proteins released not only from glioma cells, but also from GAMs, an important class is represented by the matrix metalloproteases (MMPs) [79-81], especially MMP2 and MMP-9 [76, 82, 83]. These enzymes can mediate degradation of the extracellular matrix, thus promoting invasion of the surrounding healthy tissues. In line with this idea, microvesicles shed in culture by oligodendroglioma cells were, for instance, shown to contain a TIMP3-sensitive "aggrecanase" activity, which could allow cellular invasion of aggrecan-rich extracellular matrices [23].

Importantly, migration of glioma cells throughout the brain is also guided by the brain vessels, and cancer growth is associated with angiogenesis [69]. Proliferation of BCECs, to produce the new vessels, causes disruption of the tight junctions and generalized fragility of the BBB, which becomes leaky, thus creating the conditions for the vasogenic brain edema, the most serious clinical complication of glioblastoma [69]. Edema and glioma progression have been also correlated with altered expression of different isoforms of aquaporins (AQPs), a family of water channels of the plasma membrane [84], which are upregulated in brain cancer [85-89]. Since in other systems both proteins of the tight junctions [90] and AQPs $[91,92]$ have been reported to enter exosomes, a new approach to the study of glioma-linked edema could be the search for these proteins in EVs released from brain cancers, with the additional aim of identifying further diagnostic tools. Actually, variations in the number, and possibly in the function, of EVs circulating in peripheral blood have been reported in brain tumors [93].

Importantly, aggressiveness of gliomas has been correlated with hypoxia, which should be the main inducer of both necrosis and BBB alteration. Hypoxia-dependent intercellular signalling, induced by growth factors, such as VEGF, at least in part secreted via EVs [94], stimulates not only BCECs proliferation and angiogenesis, but also activation of the coagulation system, responsible for vascular thrombosis [95]. Microvesicles have been known to be associated with coagulation since the 1940 s because they expose PS, a negatively charged phospholipid, which can allow recruitment of calcium ions and active coagulation factors. Actually, tumour-derived vesicles have an even higher coagulation potential because they carry TF (tissue factor), an initiating coagulation factor [78].

An additional serious problem, posed by brain tumours, is the cancer-induced neuronal cell death and neurodegeneration. These events are associated with cytotoxic edema [69, 96]. Again, extracellular vesicles are probably involved. For example, G26/24 oligodendroglioma cells release EVs that, when added to primary cultures of rat cortical neurons, inhibit neurite outgrowth and induce apoptosis in about $75 \%$ of the cells [16]. The same amount of EVs induces apoptosis in only $40 \%$ of astrocytes [97]. In line with these observations, vesicles released by $\mathrm{G} 26 / 24$ cells were found to contain extracellular proapoptotic ligands, such as FasL and TRAIL, which could cooperate in inducing brain cell death. As already mentioned, these effects depend, at least in part, on the horizontal transfer of proteins, mediated by the vesicles, from tumour to normal brain cells $[16,97]$.

EVs are probably also involved in expelling from cancer cells regulatory proteins. G26/24 release, for example, vesicles which carry on the differentiation-specific $\mathrm{Hl}^{\circ}$ histone variant, thus eliminating a protein otherwise able to counteract proliferation [37].

Perhaps the most intriguing property of EVs is that they contain various classes of nucleic acids and are therefore able to exert an effect on the translational profile of normal cells present in their environment [78, 98, 99]. Transfer of DNA among cells is an evolutionary conserved process: bacterial vesicles contain DNA encoding virulence genes, which can be transferred into other bacteria and then expressed [72]. EVs released from eukaryotic cells carry both DNA and RNA. For example, brain tumours release EVs which contain cMyc as well as high levels of retrotransposon RNA transcripts, such as those for LINE-1 and Alu elements; these transposable elements are then transferred to normal cells [100]. The presence of noncoding RNAs (ncRNAs) in EVs is actually one of the more fascinating topics in the field, since at least some of these RNAs have been suggested to be involved in epigenetic regulation of gene expression [101] and have thus the potential to induce profound modifications of recipient cells attitudes.

Intriguingly, exosomes released from astrocytes and glioma cells also contain mitochondrial DNA [102].

The collection of glioma-derived mRNAs, transferred into recipient cells via EVs, is actually highly complex and includes a variety of transcripts associated with proliferation, immune repression, and tissue invasion [103]; these transcripts are representative of almost all the transcriptomes of the producing cells; however, some transcripts are clearly enriched in EVs [98], thus suggesting existence of mechanisms, such as the presence of specific "zip codelike" sequences in the untranslated regions of the target passenger mRNAs [104], which allow selective sorting and/or stabilization of given mRNAs in EVs. Interestingly, many transcripts are common among EVs released from different cancer cell types [98].

Among EV-carried RNAs, a special class, which is attracting much attention, is represented by microRNAs [98]. Ten years ago, a microarray analysis allowed, for the first time, identification in glioblastoma, by two different laboratories, of aberrant miRNAs; one of which (miR21) was in particular shown to act as an antiapoptotic factor (for a review see [105]). More recently, a genome-wide miRNA expression profile allowed identification of 55 upregulated 
and 29 downregulated miRNAs in malignant gliomas, at the same time suggesting that a group of 23 miRNAs could represent a sort of signature for GBM able to distinguish it even from anaplastic astrocytoma [106]. Although more studies are requested to univocally combine all the results described in the last ten years, a few miRNAs have indeed the potential to contribute to GBM $[105,107]$.

By performing microRNA PCR array, Camacho et al. also found a difference among brain metastatic (BM) and nonbrain metastatic tumor-derived exosomes; in particular, one upregulated (miR-210) and two downregulated (miR-19a and miR-29c) miRNAs were identified in BM versus non-BM exosomes [108].

The presence of both the proteins and RNAs discussed above in glioma-derived EVs, combined with the fact that these EVs are also present in the circulation of patients with glioma, while they almost disappear after tumor removal [103], suggests that these vesicles could be used as a liquid biopsy of cancer and reflect the disease grade [109-111]. A specific biomarker for glioblastoma is, for example, the already mentioned EGFRvIII, a mutated EGF receptor which lacks the extracellular domain, and triggers a "constitutively on" signal transduction pathway. This protein is found both in tumor cells and in shed vesicles [71, 112].

Recently, the ability of tumor cells to cause damage not only by acting directly on normal cells but also by altering their extracellular environment has been also emerging [113].

Finally, it should be mentioned that exosomes may protect tumor cells from accumulating drugs, thus accounting, at least in part, for drug/multidrug resistance [78, 114]. For example, P-glycoprotein, member of the ATP binding cassette superfamily, and one of the most important drug transporters, has been shown to be exchanged among cells via EVs [115].

\section{Neurodegenerative Diseases}

As in the case of brain tumors, variations in the amount of EVs circulating in peripheral blood have been also reported in several nervous system diseases, such as Alzheimer's disease [116], dementia [117], epilepsy [118], stroke [119], and traumatic brain injury [120]. The association between EV increase and multiple sclerosis is also well documented (as reviewed in $[121,122])$, although the exact role of shed vesicles in disease progression is still unclear: it seems that they contain metalloproteinases damaging the blood-brain barrier, as well as factors involved in propagation of neuroinflammation; on the other hand, they seem to promote maturation and migration of oligodendrocyte precursor cells, necessary for repair of the damaged axons [121].

EVs can be implicated in neurodegenerative diseases also because they can deliver toxic proteins such as prions (PrPsc) [123-125], alpha-synuclein [126, 127], amyloid precursor protein (APP) or $\beta$-amyloid peptides [128-133], phosphorylated Tau [134], and SOD1 [135].

Accumulation of aggregates of abnormal proteins has indeed emerged as a common mechanism for most human neurodegenerative diseases, including Alzheimer's disease,
Parkinson's disease, frontotemporal dementias, and amyotrophic lateral sclerosis. All these diseases should propagate through the brain via prion-like intercellular induction of protein misfolding [136, 137]. Neurons are peculiar cells in that they are postmitotic and cannot selfrenew to clear abnormally folded/accumulated proteins; thus they accumulate protein folding errors, especially into aggregation-prone proteins, throughout their life-span [138]. Defects in protein degradation by the proteasomedepending pathway, because of abnormal activity of ubiquitinating/deubiquitinating enzymes, molecular chaperones, and protein hydrolases, can severely affect cell health and survival.

One of the most studied examples of the damaging effects of protein aggregation in neurons is given by the microtubuleassociated protein Tau. An increase in Tau concentration, hyperphosphorylation, and aggregation seems to be the principal agent in the transmission and spreading of tauopathies, among which is Alzheimer's disease. Intracellular accumulation of aggregated Tau has been considered over time the main source of its toxicity. However, Tau added from the extracellular side is still toxic to neuronal cells [139]. For a long time, extracellular tau was believed to come out from lysed dead neurons. More recently, however, growing evidence suggested that extracellular Tau in AD brain (and CSF) is very likely due to active secretion [140-143].

A nontransgenic lower vertebrate tauopathy model (the lamprey $\mathrm{ABC}$ model) has been used to express full-length wild type and mutant human Tau isoforms in identified neurons, thus allowing localization of toxic Tau sources. Thanks to this model system, Tau was found to be secreted before the onset of neuronal degeneration and to be transferred among neurons, thus spreading in a disease-specific pattern to the brain and playing a major role in pathogenesis [144, 145]. Association of Tau with exosomes suggests that extracellular vesicles is at least one of the routes for active interneuronal transfer of toxic protein [140]. Interestingly, it has been also found that Tau can interact with signaling components localized to the plasma membrane, such as the Src-family of nonreceptor tyrosine kinases [141, 145, 146]. This finding suggests that extracellular signaling might have an effect on Tau sorting to extracellular vesicles and spreading throughout the brain.

Similar to Tau protein, in synucleinopathies, such as Parkinson's disease, SNCA/ $\alpha$-synuclein can be released by neural cells into the extracellular space by EV shedding [125, $126]$. It has been reported that SNCA/ $\alpha$-synuclein is released in two main forms: through exosomes, which contain lowaggregated proteins, and through MVs, which contain highaggregated proteins. It seems that, while intracellular SNCA aggregation has probably a protective role, released SNCA is toxic, most probably spreading the disease throughout the brain; the toxic effect is highly enhanced when autophagylysosomal pathway is inhibited [147].

Involvement of EVs in the pathological spreading of toxic proteins has been confirmed by the presence of vesicles in the CSF. MVs derived from all the major types of neural cells are already detectable in both rodent and human CSF, under normal conditions. In the inflamed brain, in cases of multiple sclerosis in humans and experimental autoimmune 
encephalomyelitis (EAE) in mice, however, the amount of MVs increases dramatically depending on disease severity and the extent of microglia activation [148]. Exosomes enriched in prion proteins have been isolated from both ovine CSF [149] and human CSF [150].

In the late 1990s, human Tau was already evidenced in CSF of early stage patients with Alzheimer's disease [151, 152]. More recently, phosphorylated Tau has been found in exosomes, and this is a peculiar feature of $\mathrm{AD}$ with respect to both normal aging and other neurodegenerative diseases [141]. The early presence of exosome-associated Tau in CSF is of interest for at least two reasons: (1) it is a further indication of an active secretion of Tau from neurons (discussed in the previous section); (2) it could offer a powerful and noninvasive instrument for early AD diagnosis [138].

Given their potential interest in both diagnosis and basic research, EVs from the CSF have been the subjects of several studies. In particular, many efforts have been devoted to proteomic profiling of CSF exosomes [150, 153]. These analyses demonstrated the presence in CSF vesicles, among other proteins, of Alix, syntenin-1, tetraspanins, heat shock proteins, Rab proteins, transcription factors, MHC antigens, integrin alpha-M, the receptor-type tyrosine-protein phosphatase $\mathrm{C}$, enolase 2 , the dihydropyrimidinase-related protein 2 , and the vesicle-associated membrane protein 2 (VAMP2) [150].

From all the discussed studies, it is evident that EVs, if taken up from cells different from the producer ones, have the potential to promote deep modifications of properties and behavior of the recipient cells.

\section{Concluding Remarks}

In conclusion, extracellular vesicles seem to play an important role in coordinating intercellular communication in brain. Production of EVs is probably a dynamic process which can undergo both quantitative and qualitative modifications depending on neuronal activity, metabolic state, and perhaps membrane trafficking rate. In pathological conditions, such as cancer as well as neurodegeneration, EV production and release seem to be potentiated and allow secretion into the extracellular environment of proteins, RNAs, and lipids, which can horizontally transfer pathological features to the surrounding cells. The presence of disease-specific proteins and RNAs in EVs, which can also reach the patient CSF, could offer a powerful way for early detection of pathology and is certainly worth of further analyses. Finally, EVs also deserve attention as potential drug carriers, theoretically able to cross the blood-brain barrier.

\section{Conflict of Interests}

The authors declare that there is no conflict of interests.

\section{Acknowledgment}

This work was supported by the University of Palermo (ex $60 \%$ MIUR to Italia Di Liegro).

\section{References}

[1] E. Cocucci and J. Meldolesi, "Ectosomes and exosomes: shedding the confusion between extracellular vesicles," Trends in Cell Biology, vol. 25, no. 6, pp. 364-372, 2015.

[2] B. György, T. G. Szabó, M. Pásztói et al., "Membrane vesicles, current state-of-the-art: emerging role of extracellular vesicles," Cellular and Molecular Life Sciences, vol. 68, no. 16, pp. 26672688, 2011.

[3] T. Kobayashi, M. H. Beuchat, M. Lindsay et al., "Late endosomal membranes rich in lysobisphosphatidic acid regulate cholesterol transport," Nature Cell Biology, vol. 1, no. 2, pp. 113-118, 1999.

[4] K. Trajkovic, C. Hsu, S. Chiantia et al., "Ceramide triggers budding of exosome vesicles into multivesicular endosomes," Science, vol. 319, no. 5867, pp. 1244-1247, 2008.

[5] C. Bissig and J. Gruenberg, "ALIX and the multivesicular endosome: ALIX in wonderland," Trends in Cell Biology, vol. 24, no. 1, pp. 19-25, 2014.

[6] J. Kowal, M. Tkach, and C. Théry, "Biogenesis and secretion of exosomes," Current Opinion in Cell Biology, vol. 29, pp. 116-125, 2014.

[7] F. Bianco, C. Perrotta, L. Novellino et al., "Acid sphingomyelinase activity triggers microparticle release from glial cells," The EMBO Journal, vol. 28, no. 8, pp. 1043-1054, 2009.

[8] B. Shen, N. Wu, M. Yang Jr., and S. J. Gould, "Protein targeting to exosomes/microvesicles by plasma membrane anchors," Journal of Biological Chemistry, vol. 286, no. 16, pp. 14383-14395, 2011.

[9] J.-M. Yang and S. J. Gould, "The cis-acting signals that target proteins to exosomes and microvesicles," Biochemical Society Transactions, vol. 41, no. 1, pp. 277-282, 2013.

[10] L. M. Mashburn-Warren and M. Whiteley, "Special delivery: vesicle trafficking in prokaryotes," Molecular Microbiology, vol. 61, no. 4, pp. 839-846, 2006.

[11] S. J. Biller, F. Schubotz, S. E. Roggensack, A. W. Thompson, R. E. Summons, and S. W. Chisholm, "Bacterial vesicles in marine ecosystems," Science, vol. 343, no. 6167, pp. 183-186, 2014.

[12] D. Tarin, "Fine structure of murine mammary tumours: the relationship between epithelium and connective tissue in neoplasms induced by various agents," British Journal of Cancer, vol. 23, no. 2, pp. 417-425, 1969.

[13] E. G. Trams, C. J. Lauter, J. Norman Salem, and U. Heine, "Exfoliation of membrane ecto-enzymes in the form of microvesicles," Biochimica et Biophysica Acta, vol. 645, no. 1, pp. 6370, 1981.

[14] D. D. Taylor, C. G. Taylor, C. G. Jiang, and P. H. Black, "Characterization of plasma membrane shedding from murine melanoma cells," International Journal of Cancer, vol. 41, no. 4, pp. 629-635, 1988.

[15] V. Dolo, A. Ginestra, G. Ghersi, H. Nagase, and M. L. Vittorelli, "Human breast carcinoma cells cultured in the presence of serum shed membrane vesicles rich in gelatinolytic activities," Journal of Submicroscopic Cytology and Pathology, vol. 26, no. 2, pp. 173-180, 1994.

[16] S. D’Agostino, M. Salamone, I. Di Liegro, and M. L. Vittorelli, "Membrane vesicles shed by oligodendroglioma cells induce neuronal apoptosis," International Journal of Oncology, vol. 29, no. 5, pp. 1075-1085, 2006.

[17] I. A. Bab, A. Muhlrad, and J. Sela, "Ultrastructural and biochemical study of extracellular matrix vesicles in normal alveolar bone of rats," Cell and Tissue Research, vol. 202, no. 1, pp. 1-7, 1979. 
[18] N. Dainiak, "Surface membrane-associated regulation of cell assembly, differentiation, and growth," Blood, vol. 78, no. 2, pp. 264-276, 1991.

[19] G. Schiera, P. Proia, C. Alberti, M. Mineo, G. Savettieri, and I. Di Liegro, "Neurons produce FGF2 and VEGF and secrete them at least in part by shedding extracellular vesicles," Journal of Cellular and Molecular Medicine, vol. 11, no. 6, pp. 1384-1394, 2007.

[20] P. Proia, G. Schiera, M. Mineo et al., "Astrocytes shed extracellular vesicles that contain fibroblast growth factor- 2 and vascular endothelial growth factor," International Journal of Molecular Medicine, vol. 21, no. 1, pp. 63-67, 2008.

[21] J. Fauré, G. Lachenal, M. Court et al., "Exosomes are released by cultured cortical neurones," Molecular and Cellular Neuroscience, vol. 31, no. 4, pp. 642-648, 2006.

[22] N. Arraud, R. Linares, S. Tan et al., "Extracellular vesicles from blood plasma: determination of their morphology, size, phenotype and concentration," Journal of Thrombosis and Haemostasis, vol. 12, no. 5, pp. 614-627, 2014.

[23] A. Lo Cicero, I. Majkowska, H. Nagase, I. Di Liegro, and L. Troeberg, "Microvesicles shed by oligodendroglioma cells and rheumatoid synovial fibroblasts contain aggrecanase activity," Matrix Biology, vol. 31, no. 4, pp. 229-233, 2012.

[24] C. I. Matei, C. Boulocher, C. Boulé et al., "Ultrastructural analysis of healthy synovial fluids in three mammalian species," Microscopy and Microanalysis, vol. 20, no. 3, pp. 903-911, 2014.

[25] T. Chen, Q. Y. Xi, R. S. Ye et al., "Exploration of microRNAs in porcine milk exosomes," BMC Genomics, vol. 15, article 100, 2014.

[26] A. Gallo, M. Tandon, I. Alevizos, and G. G. Illei, “The majority of microRNAs detectable in serum and saliva is concentrated in exosomes," PLoS ONE, vol. 7, no. 3, Article ID e30679, 2012.

[27] Y. Ogawa, Y. Taketomi, M. Murakami, M. Tsujimoto, and R. Yanoshita, "Small RNA transcriptomes of two types of exosomes in human whole saliva determined by next generation sequencing," Biological and Pharmaceutical Bulletin, vol. 36, no. 1, pp. 66-75, 2013.

[28] N. J. Abbott, A. A. K. Patabendige, D. E. M. Dolman, S. R. Yusof, and D. J. Begley, "Structure and function of the blood-brain barrier," Neurobiology of Disease, vol. 37, no. 1, pp. 13-25, 2010.

[29] G. Schiera, E. Bono, M. P. Raffa et al., "Synergistic effects of neurons and astrocytes on the differentiation of brain capillary endothelial cells in culture," Journal of Cellular and Molecular Medicine, vol. 7, no. 2, pp. 165-170, 2003.

[30] G. Schiera, S. Sala, A. Gallo et al., "Permeability properties of a three-cell type in vitro model of blood-brain barrier," Journal of Cellular and Molecular Medicine, vol. 9, no. 2, pp. 373-379, 2005.

[31] N. Ferrara and T. Davis-Smyth, "The biology of vascular endothelial growth factor," Endocrine Reviews, vol. 18, no. 1, pp. 4-25, 1997.

[32] A. Bikfalvi, S. Klein, G. Pintucci, and D. B. Rifkin, "Biological roles of fibroblast growth factor-2," Endocrine Reviews, vol. 18, no. 1, pp. 26-45, 1997.

[33] S. Taverna, G. Ghersi, A. Ginestra et al., "Shedding of membrane vesicles mediates fibroblast growth factor-2 release from cells," Journal of Biological Chemistry, vol. 278, no. 51, pp. 51911-51919, 2003.

[34] C. Villarroya-Beltri, C. Gutiérrez-Vázquez, F. Sánchez-Cabo et al., "Sumoylated hnRNPA2B1 controls the sorting of miRNAs into exosomes through binding to specific motifs," Nature Communications, vol. 4, article 2980, 2013.
[35] A. Tietje, K. N. Maron, Y. Wei, D. M. Feliciano, and G. J. Bouma, "Cerebrospinal fluid extracellular vesicles undergo age dependent declines and contain known and novel non-coding rnas," PLoS ONE, vol. 9, no. 11, Article ID el13116, 2014.

[36] A. R. Taylor, M. B. Robinson, D. J. Gifondorwa, M. Tytell, and C. E. Milligan, "Regulation of heat shock protein 70 release in astrocytes: role of signaling kinases," Developmental Neurobiology, vol. 67, no. 13, pp. 1815-1829, 2007.

[37] G. Schiera, C. M. Di Liegro, P. Saladino et al., "Oligodendroglioma cells synthesize the differentiation-specific linker histone $\mathrm{H}^{\circ}$ and release it into the extracellular environment through shed vesicles," International Journal of Oncology, vol. 43, no. 6, pp. 1771-1776, 2013.

[38] S. Wang, F. Cesca, G. Loers et al., "Synapsin I is an oligomannose-carrying glycoprotein, acts as an oligomannosebinding lectin, and promotes neurite outgrowth and neuronal survival when released via glia-derived exosomes," Journal of Neuroscience, vol. 31, no. 20, pp. 7275-7290, 2011.

[39] O. Sbai, A. Ould-Yahoui, L. Ferhat et al., "Differential vesicular distribution and trafficking of MMP-2, MMP-9, and their inhibitors in astrocytes," Glia, vol. 58, no. 3, pp. 344-366, 2010.

[40] G. Lachenal, K. Pernet-Gallay, M. Chivet et al., "Release of exosomes from differentiated neurons and its regulation by synaptic glutamatergic activity," Molecular and Cellular Neuroscience, vol. 46, no. 2, pp. 409-418, 2011.

[41] M. Chivet, F. Hemming, K. Pernet-Gallay, S. Fraboulet, and R. Sadoul, "Emerging role of neuronal exosomes in the central nervous system," Frontiers in Physiology, vol. 3, article 145, 2012.

[42] C. Frühbeis, D. Fröhlich, W. P. Kuo, and E.-M. Krämer-Albers, "Extracellular vesicles as mediators of neuron-glia communication," Frontiers in Cellular Neuroscience, vol. 7, article 182, 2013.

[43] U. Fünfschilling, L. M. Supplie, D. Mahad et al., "Glycolytic oligodendrocytes maintain myelin and long-term axonal integrity," Nature, vol. 485, no. 7399, pp. 517-521, 2012.

[44] Y. Lee, B. M. Morrison, Y. Li et al., "Oligodendroglia metabolically support axons and contribute to neurodegeneration," Nature, vol. 487, no. 7408, pp. 443-448, 2012.

[45] E.-M. Krämer-Albers, N. Bretz, S. Tenzer et al., "Oligodendrocytes secrete exosomes containing major myelin and stressprotective proteins: trophic support for axons?" ProteomicsClinical Applications, vol. 1, no. 11, pp. 1446-1461, 2007.

[46] J. R. Sotelo, L. Canclini, A. Kun et al., "Myosin-Va-dependent cell-to-cell transfer of RNA from Schwann cells to axons," PLoS ONE, vol. 8, no. 4, Article ID e61905, 2013.

[47] C. Frühbeis, D. Fröhlich, W. P. Kuo et al., "Neurotransmittertriggered transfer of exosomes mediates oligodendrocyteneuron communication," PLoS Biology, vol. 11, no. 7, Article ID e1001604, 2013.

[48] D. Fröhlich, W. P. Kuo, C. Frühbeis et al., "Multifaceted effects of oligodendroglial exosomes on neurons: impact on neuronal firing rate, signal transduction and gene regulation," Philosophical Transactions of the Royal Society of London. Series B: Biological Sciences, vol. 369, no. 1652, 2014.

[49] C. M. Di Liegro, G. Schiera, and I. Di Liegro, "Regulation of mRNA transport, localizationand translation in the nervous system of mammals (Review)," International Journal of Molecular Medicine, vol. 33, no. 4, pp. 747-762, 2014.

[50] E. Koenig, "Organized ribosome-containing structural domains in axons," Results and Problems in Cell Differentiation, vol. 48, pp. 173-191, 2009. 
[51] J. Tcherkezian, P. A. Brittis, F. Thomas, P. P. Roux, and J. G. Flanagan, "Transmembrane receptor DCC associates with protein synthesis machinery and regulates translation," Cell, vol. 141, no. 4, pp. 632-644, 2010.

[52] F. A. Court, W. T. J. Hendriks, H. D. MacGillavry, J. Alvarez, and J. Van Minnen, "Schwann cell to axon transfer of ribosomes: toward a novel understanding of the role of glia in the nervous system," Journal of Neuroscience, vol. 28, no. 43, pp. 11024-11029, 2008.

[53] J. L. Twiss and M. Fainzilber, "Ribosomes in axons-scrounging from the neighbors?" Trends in Cell Biology, vol. 19, no. 5, pp. 236-243, 2009.

[54] F. A. Court, R. Midha, B. A. Cisterna et al., "Morphological evidence for a transport of ribosomes from Schwann cells to regenerating axons," Glia, vol. 59, no. 10, pp. 1529-1539, 2011.

[55] J. R. Sotelo, L. Canclini, A. Kun et al., "Glia to axon RNA transfer," Developmental Neurobiology, vol. 74, no. 3, pp. 292302,2014

[56] F. Bianco, E. Pravettoni, A. Colombo et al., "Astrocyte-derived ATP induces vesicle shedding and IL-1 $\beta$ release from microglia," Journal of Immunology, vol. 174, no. 11, pp. 7268-7277, 2005.

[57] I. Prada, R. Furlan, M. Matteoli, and C. Verderio, "Classical and unconventional pathways of vesicular release in microglia," Glia, vol. 61, no. 7, pp. 1003-1017, 2013.

[58] F. Antonucci, E. Turola, L. Riganti et al., "Microvesicles released from microglia stimulate synaptic activity via enhanced sphingolipid metabolism," EMBO Journal, vol. 31, no. 5, pp. 1231-1240, 2012.

[59] M. Gabrielli, N. Battista, L. Riganti et al., "Active endocannabinoids are secreted on extracellular membrane vesicles," The EMBO Reports, vol. 16, no. 2, pp. 213-220, 2015.

[60] I. Y. Tamboli, E. Barth, L. Christian et al., "Statins promote the degradation of extracellular amyloid beta-peptide by microglia via stimulation of exosome-associated insulindegrading enzyme (IDE) secretion," The Journal of Biological Chemistry, vol. 285, no. 48, pp. 37405-37414, 2010.

[61] A. S. Haqqani, C. E. Delaney, T.-L. Tremblay, C. Sodja, J. K. Sandhu, and D. B. Stanimirovic, "Method for isolation and molecular characterization of extracellular microvesicles released from brain endothelial cells," Fluids and Barriers of the CNS, vol. 10, no. 1, article 4, 2013.

[62] M. Chivet, C. Javalet, K. Laulagnier, B. Blot, F. J. Hemming, and R. Sadoul, "Exosomes secreted by cortical neurons upon glutamatergic synapse activation specifically interact with neurons," Journal of Extracellular Vesicles, vol. 3, Article ID 24722, 2014.

[63] G. N. Fuller and B. W. Scheithauer, "The 2007 revised World Health Organization (WHO) classification of tumours of the central nervous system: newly codified entities," Brain Pathology, vol. 17, no. 3, pp. 304-307, 2007.

[64] D. N. Louis, H. Ohgaki, O. D. Wiestler et al., "The 2007 WHO classification of tumours of the central nervous system," Acta Neuropathologica, vol. 114, no. 2, pp. 97-109, 2007.

[65] I. Jovčevska, "Glioma and glioblastoma-how much do we (not) know? (Review)," Molecular and Clinical Oncology, vol. 1, no. 6, pp. 935-941, 2013.

[66] E. C. Burton and M. D. Prados, "Malignant gliomas," Current Treatment Options in Oncology, vol. 1, no. 5, pp. 459-468, 2000.

[67] W. Taal, J. E. Bromberg, and M. J. van den Bent, "Chemotherapy in glioma," CNS Oncology, vol. 4, no. 3, pp. 179-192, 2015.

[68] F. Zhang, C. L. Xu, and C. M. Liu, "Drug delivery strategies to enhance the permeability of the blood-brain barrier for treatment of glioma," Drug Design, Development and Therapy, vol. 9, pp. 2089-2100, 2015.

[69] L. G. Dubois, L. Campanati, C. Righy et al., "Gliomas and the vascular fragility of the blood brain barrier," Frontiers in Cellular Neuroscience, vol. 8, article 418, 13 pages, 2014.

[70] E. Pap, É. Pállinger, and A. Falus, “The role of membrane vesicles in tumorigenesis," Critical Reviews in Oncology/Hematology, vol. 79, no. 3, pp. 213-223, 2011.

[71] K. Al-Nedawi, B. Meehan, J. Micallef et al., "Intercellular transfer of the oncogenic receptor EGFRvIII by microvesicles derived from tumour cells," Nature Cell Biology, vol. 10, no. 5, pp. 619-624, 2008.

[72] R. Nieuwland and A. Sturk, "Why do cells release vesicles?" Thrombosis Research, vol. 125, supplement 1, pp. S49-S51, 2010.

[73] E. H. Wilson, W. Weninger, and C. A. Hunter, "Trafficking of immune cells in the central nervous system," Journal of Clinical Investigation, vol. 120, no. 5, pp. 1368-1379, 2010.

[74] C. Cossetti, J. A. Smith, N. Iraci, T. Leonardi, C. Alfaro-Cervello, and S. Pluchino, "Extracellular membrane vesicles and immune regulation in the brain," Frontiers in Physiology, vol. 3, article 117, 2012.

[75] R. Fu, Q. Shen, P. Xu, J. J. Luo, and Y. Tang, "Phagocytosis of microglia in the central nervous system diseases," Molecular Neurobiology, vol. 49, pp. 1422-1434, 2014.

[76] T. Wurdinger, K. Deumelandt, H. J. van der Vliet, P. Wesseling, and T. D. de Gruijl, "Mechanisms of intimate and long-distance cross-talk between glioma and myeloid cells: how to break a vicious cycle," Biochimica et Biophysica Acta (BBA)-Reviews on Cancer, vol. 1846, no. 2, pp. 560-575, 2014.

[77] M. Record, C. Subra, S. Silvente-Poirot, and M. Poirot, "Exosomes as intercellular signalosomes and pharmacological effectors," Biochemical Pharmacology, vol. 81, no. 10, pp. 1171-1182, 2011.

[78] E. van der Pol, A. N. Böing, P. Harrison, A. Sturk, and R. Nieuwland, "Classification, functions, and clinical relevance of extracellular vesicles," Pharmacological Reviews, vol. 64, no. 3, pp. 676-705, 2012.

[79] J. S. Rao, "Molecular mechanisms of glioma invasiveness: the role of proteases," Nature Reviews Cancer, vol. 3, no. 7, pp. 489501, 2003.

[80] A. C. Bellail, S. B. Hunter, D. J. Brat, C. Tan, and E. G. Van Meir, "Microregional extracellular matrix heterogeneity in brain modulates glioma cell invasion," International Journal of Biochemistry and Cell Biology, vol. 36, no. 6, pp. 1046-1069, 2004.

[81] A. M. Costa, F. Pinto, O. Martinho, M. J. Oliveira, P. Jordan, and R. M. Reis, "Silencing of the tumor suppressor gene WNK2 is associated with upregulation of MMP2 and JNK in gliomas," Oncotarget, vol. 6, no. 3, pp. 1422-1434, 2015.

[82] P. O. Esteve, P. Tremblay, M. Houde, Y. St-Pierre, and R. Mandeville, "In vitro expression of MMP-2 and MMP-9 in glioma cells following exposure to inflammatory mediators," Biochimica et Biophysica Acta-Molecular Cell Research, vol. 1403, no. 1, pp. 85-96, 1998.

[83] H. Könnecke and I. Bechmann, "The role of microglia and matrix metalloproteinases involvement in neuroinflammation and gliomas," Clinical and Developmental Immunology, vol. 2013, Article ID 914104, 15 pages, 2013.

[84] M. C. Papadopoulos and A. S. Verkman, "Aquaporin water channels in the nervous system," Nature Reviews Neuroscience, vol. 14, no. 4, pp. 265-277, 2013. 
[85] E. McCoy and H. Sontheimer, "Expression and function of water channels (aquaporins) in migrating malignant astrocytes," Glia, vol. 55, no. 10, pp. 1034-1043, 2007.

[86] S. Noell, R. Ritz, K. Wolburg-Buchholz, H. Wolburg, and P. Fallier-Becker, "An allograft glioma model reveals the dependence of aquaporin-4 expression on the brain microenvironment," PLoS ONE, vol. 7, Article ID e36555, 2012.

[87] G. Fossdal, E. O. Vik-Mo, C. Sandberg et al., "Aqp 9 and brain tumour stem cells," The Scientific World Journal, vol. 2012, Article ID 915176, 9 pages, 2012.

[88] E. J. Suero Molina, H. Ardon, J. Schroeteler et al., "Aquaporin4 in glioma and metastatic tissues harboring 5-aminolevulinic acid-induced porphyrin fluorescence," Clinical Neurology and Neurosurgery, vol. 115, no. 10, pp. 2075-2081, 2013.

[89] S. J. Zhu, K. J. Wang, S. W. Gan, J. Xu, S. Y. Xu, and S. Q. Sun, "Expression of aquaporin8 in human astrocytomas: correlation with pathologic grade," Biochemical and Biophysical Research Communications, vol. 440, no. 1, pp. 168-172, 2013.

[90] J. Li, C. A. Sherman-Baust, M. Tsai-Turton, R. E. Bristow, R. B. Roden, and P. J. Morin, "Claudin-containing exosomes in the peripheral circulation of women with ovarian cancer," $B M C$ cancer, vol. 9, p. 244, 2009.

[91] L. Blanc, J. Liu, M. Vidal, J. A. Chasis, X. An, and N. Mohandas, "The water channel aquaporin-1 partitions into exosomes during reticulocyte maturation: implication for the regulation of cell volume," Blood, vol. 114, no. 18, pp. 3928-3934, 2009.

[92] J. M. Street, W. Birkhoff, R. I. Menzies, D. J. Webb, M. A. Bailey, and J. W. Dear, "Exosomal transmission of functional aquaporin 2 in kidney cortical collecting duct cells," Journal of Physiology, vol. 589, no. 24, pp. 6119-6127, 2011.

[93] M. Noerholm, L. Balaj, T. Limperg et al., "RNA expression patterns in serum microvesicles from patients with glioblastoma multiforme and controls," BMC Cancer, vol. 12, article 22, 2012.

[94] P. Kucharzewska, H. C. Christianson, J. E. Welch et al., "Exosomes reflect the hypoxic status of glioma cells and mediate hypoxia-dependent activation of vascular cells during tumor development," Proceedings of the National Academy of Sciences of the United States of America, vol. 110, no. 18, pp. 7312-7317, 2013.

[95] K. J. Svensson, P. Kucharzewska, H. C. Christianson et al., "Hypoxia triggers a proangiogenic pathway involving cancer cell microvesicles and PAR-2-mediated heparin-binding EGF signaling in endothelial cells," Proceedings of the National Academy of Sciences of the United States of America, vol. 108, no. 32, pp. 13147-13152, 2011.

[96] D. Liang, S. Bhatta, V. Gerzanich, and J. M. Simard, "Cytotoxic edema: mechanisms of pathological cell swelling," Neurosurgical focus, vol. 22, no. 5, p. E2, 2007.

[97] A. Lo Cicero, G. Schiera, P. Proia et al., "Oligodendroglioma cells shed microvesicles which contain TRAIL as well as molecular chaperones and induce cell death in astrocytes," International Journal of Oncology, vol. 39, no. 6, pp. 1353-1357, 2011.

[98] K. E. van der Vos, L. Balaj, J. Skog, and X. O. Breakefield, "Brain tumor microvesicles: insights into intercellular communication in the nervous system," Cellular and Molecular Neurobiology, vol. 31, no. 6, pp. 949-959, 2011.

[99] C. C. Y. Li, S. A. Eaton, P. E. Young et al., "Glioma microvesicles carry selectively packaged coding and noncoding RNAs which alter gene expression in recipient cells," RNA Biology, vol. 10, no. 8, pp. 1333-1344, 2013.
[100] L. Balaj, R. Lessard, L. Dai et al., "Tumour microvesicles contain retrotransposon elements and amplified oncogene sequences," Nature Communications, vol. 2, no. 1, p. 180, 2011.

[101] T. C. Roberts, K. V. Morris, and M. S. Weinberg, "Perspectives on the mechanism of transcriptional regulation by long noncoding RNAs," Epigenetics, vol. 9, no. 1, pp. 13-20, 2014.

[102] M. Guescini, S. Genedani, V. Stocchi, and L. F. Agnati, "Astrocytes and Glioblastoma cells release exosomes carrying mtDNA," Journal of Neural Transmission, vol. 117, no. 1, pp. 1-4, 2010.

[103] J. Skog, T. Würdinger, S. van Rijn et al., "Glioblastoma microvesicles transport RNA and proteins that promote tumour growth and provide diagnostic biomarkers," Nature Cell Biology, vol. 10, no. 12, pp. 1470-1476, 2008.

[104] E. D’Asti, D. Garnier, T. H. Lee, L. Montermini, B. Meehan, and J. Rak, "Oncogenic extracellular vesicles in brain tumor progression," Frontiers in Physiology, vol. 3, article 294, 2012.

[105] M. Mizoguchi, Y. Guan, K. Yoshimoto et al., "Clinical implications of microRNAs in human glioblastoma," Frontiers in Oncology, vol. 3, article 19, Article ID Article 00019, 2013.

[106] S. A. M. Rao, V. Santosh, and K. Somasundaram, "Genomewide expression profiling identifies deregulated miRNAs in malignant astrocytoma," Modern Pathology, vol. 23, no. 10, pp. 1404-1417, 2010.

[107] A. Bronisz, Y. Wang, M. O. Nowicki et al., "Extracellular vesicles modulate the glioblastoma microenvironment via a tumor suppression signaling network directed by miR-1," Cancer Research, vol. 74, no. 3, pp. 738-750, 2014.

[108] L. Camacho, P. Guerrero, and D. Marchetti, "MicroRNA and protein profiling of brain metastasis competent cell-derived exosomes," PLoS ONE, vol. 8, no. 9, Article ID e73790, 2013.

[109] D. A. Chistiakov and V. P. Chekhonin, "Extracellular vesicles shed by glioma cells: pathogenic role and clinical value," Tumor Biology, vol. 35, no. 9, pp. 8425-8438, 2014.

[110] F. H. Hochberg, N. A. Atai, D. Gonda et al., "Glioma diagnostics and biomarkers: an ongoing challenge in the field of medicine and science," Expert Review of Molecular Diagnostics, vol. 14, no. 4, pp. 439-452, 2014.

[111] D. R. Santiago-Dieppa, J. Steinberg, D. Gonda, V. J. Cheung, B. S. Carter, and C. C. Chen, "Extracellular vesicles as a platform for 'liquid biopsy' in glioblastoma patients," Expert Review of Molecular Diagnostics, vol. 14, no. 7, pp. 819-825, 2014.

[112] J. S. Redzic, T. H. Ung, and M. W. Graner, "Glioblastoma extracellular vesicles: reservoirs of potential biomarkers," Pharmacogenomics and Personalized Medicine, vol. 7, no. 1, pp. 65-77, 2014.

[113] L. Vannucci, "Stroma as an active player in the development of the tumor microenvironment," Cancer Microenvironment, 2014.

[114] R. Safaei, B. J. Larson, T. C. Cheng et al., "Abnormal lysosomal trafficking and enhanced exosomal export of cisplatin in drugresistant human ovarian carcinoma cells," Molecular Cancer Therapeutics, vol. 4, no. 10, pp. 1595-1604, 2005.

[115] J. Gong, R. Jaiswal, J.-M. Mathys, V. Combes, G. E. R. Grau, and M. Bebawy, "Microparticles and their emerging role in cancer multidrug resistance," Cancer Treatment Reviews, vol. 38, no. 3, pp. 226-234, 2012.

[116] M. S. Fiandaca, D. Kapogiannis, M. Mapstone et al., "Identification of preclinical Alzheimer's disease by a profile of pathogenic proteins in neurally derived blood exosomes: a case-control study," Alzheimer's \& Dementia, 2014. 
[117] F. Agosta, D. Dalla Libera, E. G. Spinelli et al., "Myeloid microvesicles in cerebrospinal fluid are associated with myelin damage and neuronal loss in mild cognitive impairment and Alzheimer disease," Annals of Neurology, vol. 76, no. 6, pp. 813$825,2014$.

[118] H. B. Huttner, D. Corbeil, C. Thirmeyer et al., "Increased membrane shedding-indicated by an elevation of CD133-enriched membrane particles-into the CSF in partial epilepsy," Epilepsy Research, vol. 99, no. 1-2, pp. 101-106, 2012.

[119] D. A. Kanhai, F. L. J. Visseren, Y. van der Graaf et al., "Microvesicle protein levels are associated with increased risk for future vascular events and mortality in patients with clinically manifest vascular disease," International Journal of Cardiology, vol. 168, no. 3, pp. 2358-2363, 2013.

[120] D. D. Taylor and C. Gercel-Taylor, "Exosome platform for diagnosis and monitoring of traumatic brain injury," Philosophical Transactions of the Royal Society of London. Series B, Biological Sciences, vol. 369, no. 1652, Article ID 20130503, 2014.

[121] M. Sáenz-Cuesta, I. Osorio-Querejeta, and D. Otaegui, "Extracellular vesicles in multiple sclerosis: what are they telling us?" Frontiers in Cellular Neuroscience, vol. 8, article 100, 2014.

[122] E. Colombo, B. Borgiani, C. Verderio, and R. Furlan, "Microvesicles: novel biomarkers for neurological disorders," Frontiers in Physiology, vol. 3, article 63, 2012.

[123] B. Fevrier, D. Vilette, F. Archer et al., "Cells release prions in association with exosomes," Proceedings of the National Academy of Sciences of the United States of America, vol. 101, no. 26, pp. 9683-9688, 2004.

[124] P. Saá, O. Yakovleva, J. de Castro et al., "First demonstration of transmissible spongiform encephalopathy-associated prion protein (PrPTSE) in extracellular vesicles from plasma of mice infected with mouse-adapted variant Creutzfeldt-Jakob disease by in vitro amplification," The Journal of Biological Chemistry, vol. 289, no. 42, pp. 29247-29260, 2014.

[125] B. M. Coleman and A. F. Hill, "Extracellular vesicles-their role in the packaging and spread of misfolded proteins associated with neurodegenerative diseases," Seminars in Cell \& Developmental Biology, vol. 40, pp. 89-96, 2015.

[126] E. Emmanouilidou, K. Melachroinou, T. Roumeliotis et al., "Cell-produced alpha-synuclein is secreted in a calciumdependent manner by exosomes and impacts neuronal survival," The Journal of Neuroscience, vol. 30, no. 20, pp. 6838-6851, 2010.

[127] T. Tsunemi, K. Hamada, and D. Krainc, "ATP13A2/PARK9 regulates secretion of exosomes and $\alpha$-synuclein," Journal of Neuroscience, vol. 34, no. 46, pp. 15281-15287, 2014.

[128] L. Rajendran, M. Honsho, T. R. Zahn et al., "Alzheimer's disease $\beta$-amyloid peptides are released in association with exosomes," Proceedings of the National Academy of Sciences of the United States of America, vol. 103, no. 30, pp. 11172-11177, 2006.

[129] V. Vingtdeux, M. Hamdane, A. Loyens et al., "Alkalizing drugs induce accumulation of amyloid precursor protein by-products in luminal vesicles of multivesicular bodies," The Journal of Biological Chemistry, vol. 282, no. 25, pp. 18197-18205, 2007.

[130] M. Merezhko, P. Muggalla, N. Nykänen et al., "Multiplex assay for live-cell monitoring of cellular fates of amyloid- $\beta$ precursor protein (APP)," PLoS ONE, vol. 9, no. 6, Article ID e98619, 2014.

[131] R. A. Sharples, L. J. Vella, R. M. Nisbet et al., "Inhibition of $\gamma$-secretase causes increased secretion of amyloid precursor protein C-terminal fragments in association with exosomes," The FASEB Journal, vol. 22, no. 5, pp. 1469-1478, 2008.
[132] M. B. Dinkins, S. Dasgupta, G. Wang, G. Zhu, and E. Bieberich, "Exosome reduction invivo is associated with lower amyloid plaque load in the 5XFAD mouse model of Alzheimer's disease," Neurobiology of Aging, vol. 35, no. 8, pp. 1792-1800, 2014.

[133] P. Joshi, E. Turola, A. Ruiz et al., "Microglia convert aggregated amyloid- $\beta$ into neurotoxic forms through the shedding of microvesicles," Cell Death and Differentiation, vol. 21, no. 4, pp. 582-593, 2014.

[134] M. Chivet, C. Javalet, F. Hemming et al., "Exosomes as a novel way of interneuronal communication," Biochemical Society Transactions, vol. 41, no. 1, pp. 241-244, 2013.

[135] M. Basso, S. Pozzi, M. Tortarolo et al., "Mutant copper-zinc superoxide dismutase (SOD1) induces protein secretion pathway alterations and exosome release in astrocytes: implications for disease spreading and motor neuron pathology in amyotrophic lateral sclerosis," The Journal of Biological Chemistry, vol. 288, no. 22, pp. 15699-15711, 2013.

[136] P. Novak, M. Prcina, and E. Kontsekova, "Tauons and prions: infamous cousins?" Journal of Alzheimer's Disease, vol. 26, no. 3, pp. 413-430, 2011.

[137] M. E. Kabir and J. G. Safar, "Implications of prion adaptation and evolution paradigm for human neurodegenerative diseases," Prion, vol. 8, no. 1, pp. 111-116, 2014.

[138] K. L. Gendreau and G. F. Hall, "Tangles, toxicity, and tau secretion in $\mathrm{AD}$ - new approaches to a vexing problem," Frontiers in Neurology, vol. 4, article 160, 2013.

[139] A. Gómez-Ramos, M. Díaz-Hernández, R. Cuadros, F. Hernández, and J. Avila, "Extracellular tau is toxic to neuronal cells," FEBS Letters, vol. 580, no. 20, pp. 4842-4850, 2006.

[140] G. F. Hall and S. Saman, "Death or secretion?: The demise of a plausible assumption about CSF-tau in alzheimer disease?" Communicative and Integrative Biology, vol. 5, no. 6, pp. 623626, 2012.

[141] S. Saman, W. Kim, M. Raya et al., "Exosome-associated tau is secreted in tauopathy models and is selectively phosphorylated in cerebrospinal fluid in early Alzheimer disease," Journal of Biological Chemistry, vol. 287, no. 6, pp. 3842-3849, 2012.

[142] N. Bhatia and G. F. Hall, "Untangling the role of tau in Alzheimer's disease: a unifying hypothesis," Translational Neuroscience, vol. 4, no. 2, pp. 115-133, 2013.

[143] J. Avila, D. Simón, M. Díaz-Hernández, J. Pintor, and F. Hernández, "Sources of extracellular tau and its signaling," Journal of Alzheimer's Disease, vol. 40, no. 1, pp. S7-S15, 2014.

[144] W. Kim, S. Lee, C. Jung, A. Ahmed, G. Lee, and G. F. Hall, "Interneuronal transfer of human tau between lamprey central neurons in situ," Journal of Alzheimer's Disease, vol. 19, no. 2, pp. 647-664, 2010.

[145] M. N. Le, W. Kim, S. Lee, A. C. McKee, and G. F. Hall, "Multiple mechanisms of extracellular tau spreading in a non-transgenic tauopathy model," American Journal of Neurodegenerative Disease, vol. 1, no. 3, pp. 316-333, 2012.

[146] G. Lee, "Tau and src family tyrosine kinases," Biochimica et Biophysica Acta-Molecular Basis of Disease, vol. 1739, no. 2-3, pp. 323-330, 2005.

[147] A. Poehler, W. Xiang, P. Spitzer et al., "Autophagy modulates SNCA $/ \alpha$-synuclein release, thereby generating a hostile microenvironment," Autophagy, vol. 10, no. 12, pp. 2171-2192, 2015.

[148] C. Verderio, L. Muzio, E. Turola et al., "Myeloid microvesicles are a marker and therapeutic target for neuroinflammation," Annals of Neurology, vol. 72, no. 4, pp. 610-624, 2012. 
[149] L. J. Vella, D. L. V. Greenwood, R. Cappai, J.-P. Y. Scheerlinck, and A. F. Hill, "Enrichment of prion protein in exosomes derived from ovine cerebral spinal fluid," Veterinary Immunology and Immunopathology, vol. 124, no. 3-4, pp. 385-393, 2008.

[150] D. Chiasserini, J. R. T. van Weering, S. R. Piersma et al., "Proteomic analysis of cerebrospinal fluid extracellular vesicles: a comprehensive dataset," Journal of Proteomics, vol. 106, pp. 191-204, 2014.

[151] H. Arai, M. Terajima, M. Miura et al., "Tau in cerebrospinal fluid: a potential diagnostic marker in Alzheimer's disease," Annals of Neurology, vol. 38, no. 4, pp. 649-652, 1995.

[152] G. V. W. Johnson, P. Seubert, T. M. Cox, R. Motter, J. P. Brown, and D. Galasko, "The $\tau$ protein in human cerebrospinal fluid in Alzheimer's disease consists of proteolytically derived fragments," Journal of Neurochemistry, vol. 68, no. 1, pp. 430433, 1997.

[153] J. M. Street, P. E. Barran, C. L. Mackay et al., "Identification and proteomic profiling of exosomes in human cerebrospinal fluid," Journal of Translational Medicine, vol. 10, no. 1, article 5, 2012. 

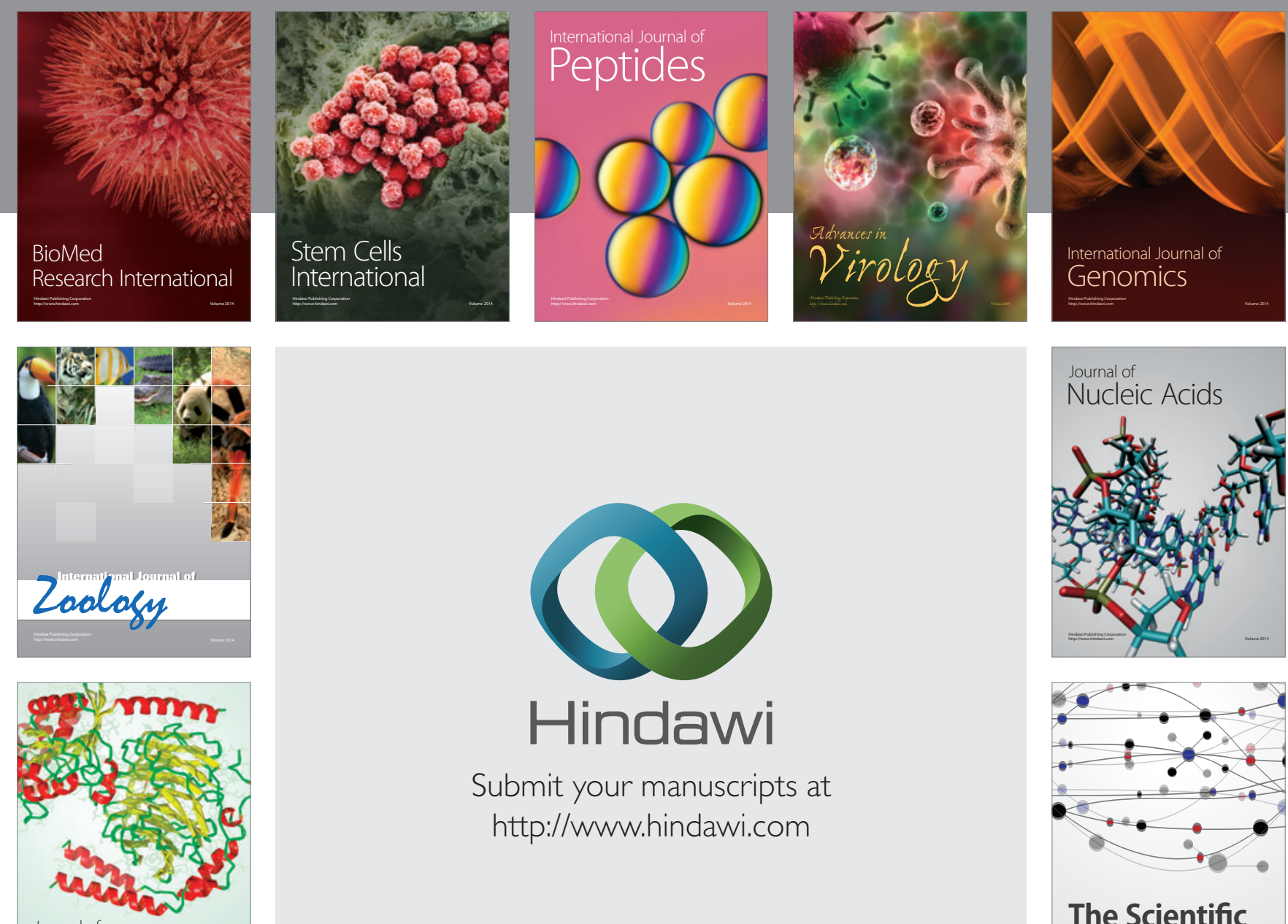

Submit your manuscripts at

http://www.hindawi.com

Journal of
Signal Transduction
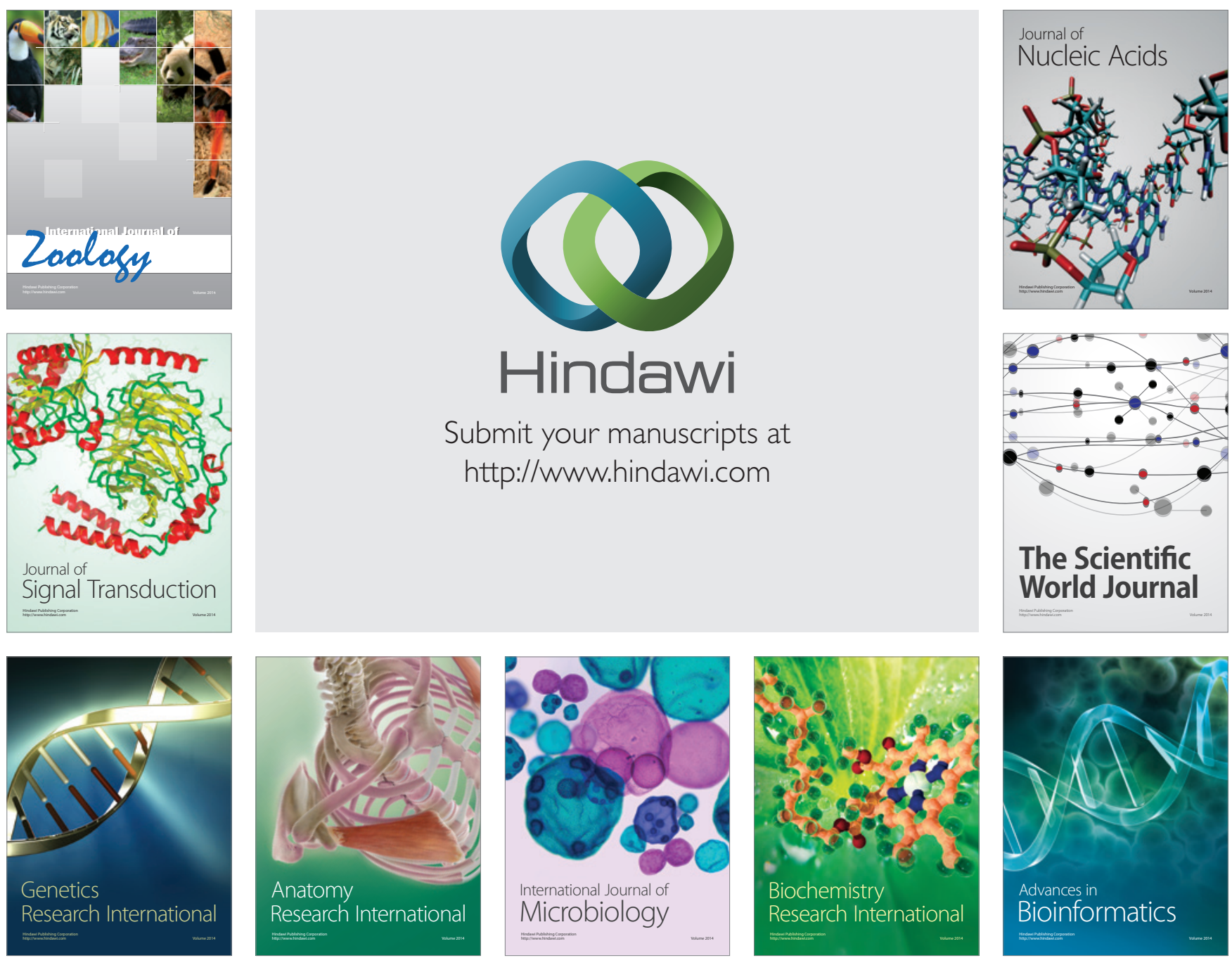

The Scientific World Journal
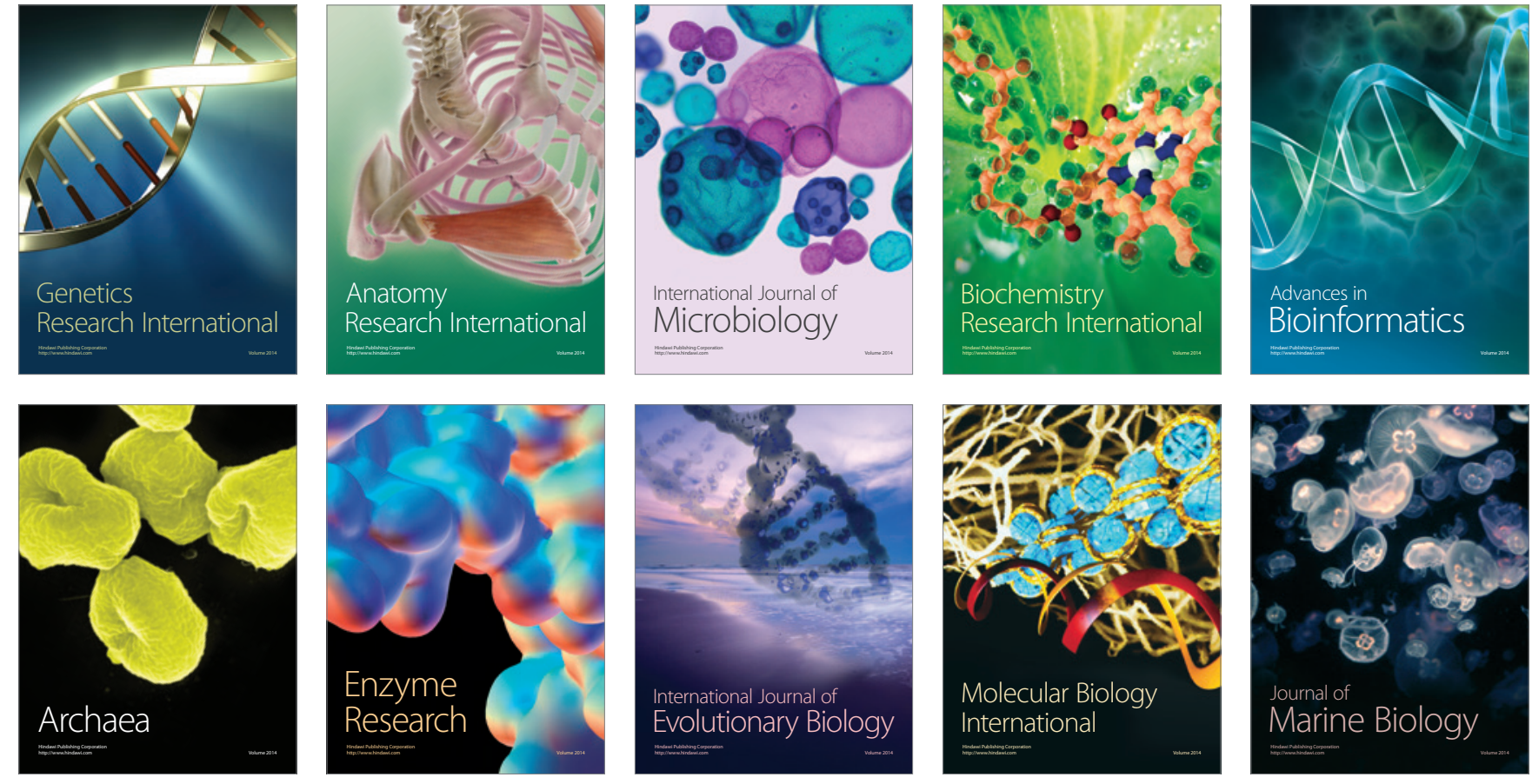